\title{
Molecular mapping and transfer of a novel brown planthopper resistance gene bph42 from Oryza rufipogon (Griff.) to cultivated rice (Oryza sativa L.)
}

pavneet Kaur

Punjab Agricultural University

Kumari Neelam ( $\square$ kneelam@pau.edu)

Punjab Agricultural University https://orcid.org/0000-0001-7816-3860

Preetinder Singh Sarao

Punjab Agricultural University

\section{Ankita Babbar}

Punjab Agricultural University

\section{Kishor Kumar}

integrated Rural Development and Management Faculty center

yogesh vikal

Punjab Agricultural University

\section{Renu Khanna}

Punjab Agricultural University

\section{Rupinder Kaur}

Punjab Agricultural University

\section{G.S. Mangat}

Punjab Agricultural University

\section{Kuldeep Singh}

PAU: Punjab Agricultural University

\section{Research Article}

Keywords: Brown planthopper, Oryza rufipogon, QTL mapping, Linkage map, Bulked segregant analysis, Marker-assisted selection

Posted Date: March 23rd, 2022

DOl: https://doi.org/10.21203/rs.3.rs-1287740/v2

License: (c) (i) This work is licensed under a Creative Commons Attribution 4.0 International License. Read Full License 


\section{Abstract}

Brown planthopper (BPH), Nilaparvata lugens (Stål), is one of the most destructive pests of rice accounting for $52 \%$ of annual yield loss. Under severe conditions, BPH cause "hopper burn" leading to drying and lodging of the matured plant. Utilization of host-plant resistance from diverse germplasm is considered a cost-effective and environment-friendly approach for its management. The current study reports the identification and mapping of a novel source of resistance from wild species of rice O. rufipogon accession CR100441 against the BPH biotype 4. Genetic analysis was performed using $276 \mathrm{BC}_{2} \mathrm{~F}_{2}$ and $233 \mathrm{BC}_{2} \mathrm{~F}_{3}$ populations derived from a cross of $O$. rufipogon accession CR100441 and highly susceptible cultivar PR122. The segregation of susceptible to resistant plants 3:1 ratio $\left(210: 66, \chi^{2} c=0.17 \leq \chi^{2}{ }_{0.05,1}=3.84\right)$ indicates the presence of a single major recessive gene. Genotyping using polymorphic microsatellite markers between PR122 and O.rufipogon acc.CR100441 spanning all the 12 chromosomes of rice was done. A total of 537 SSR markers were used to map a BPH resistance gene (designated as bph42) on the short arm of chromosome 4 between RM16282 and RM16335. QTL analysis identified a peak marker RM16335 contributing $29 \%$ of the phenotypic variance at 40.76 LOD. This marker co-segregates with the bph 42 which could be efficiently used for marker-assisted selection (MAS) to transfer the traits into elite rice cultivars.

\section{Introduction}

Rice (Oryza sativa L.) is one of the staple food crops that supply a major dietary calorific intake to one-third of the human population, globally. Rapid climate change and various abiotic and biotic stresses are the major constraints of global rice productivity. Rice productivity has been constantly challenged by insects, pests, and diseases through the rapid evolution of resistant pathotypes/biotypes. Among the insect-pests, Brown planthopper (BPH) Nilaparvata lugens (Stål) is a major pest of rice that hampers grain yield by feeding and crippling the host plant. BPH extracts the food assimilates of rice plants using its stylet type mouthparts by sucking plant sap and oviposit their eggs in stems (Rashid et al. 2017). The outbreaks of BPH cause yield loss up to $60 \%$ under high infestation (Srivastava et al. 2009, Kumar et al. 2012). Both nymphs and adults feed by sucking the cell saps of rice leaves which lead to dehydration of leaves, decrease in the number of tillers, retardation of plant growth, and development. BPH causes serious damage on rice plants directly by feeding on phloem sap giving a scorched appearance called 'hopper burn' (Elanchezhyan et al. 2020) and in most severe cases kills the entire plant during flowering. BPH indirectly damages the rice crop by transmitting ragged stunt virus (RRSV) and grassy stunt virus (RGSV) diseases (Zheng et al. 2020). It has been reported $\sim 10-40 \%$ yield loss due to these viruses (Win et al. 2011). Therefore, it is an urgent need to control BPH to ensure global food security.

Numerous pesticides have been recommended to control BPH infestation; however, the excessive use of these chemical pesticides leads to a resurgence of resistance in BPH biotypes and poses a high risk of environmental pollution (Frisvold 2019). Therefore, identification and utilization of host plant resistance from landraces and wild germplasm to develop resistant rice cultivars are considered as one of the most effective, economic, and environment-friendly approaches to manage BPH (Bisht et al. 2019). The program for genetic analysis and identification of the BPH resistance gene started in 1968 (Pathak et al. 1969). Afterward, numerous efforts were made to explore and identify BPH resistance genes from diverse germplasm resources. So far, 41 genes/QTLs have been identified from cultivated and wild species of rice and assigned to different chromosomes of rice. Among them, nine genes (Bph14, Bph3/Bph17, Bph26, bph29, Bph18, Bph6, Bph32, Bph9, and Bph30) have been isolated using the positional cloning approach (Kumar et al. 2020). Most of the BPH resistance genes are found in clusters on the rice chromosome. For example, Bph3/Bph17 (Sun et al. 2005), Bph6 (Qiu et al. 2010), Bph12(t) (Yang et al. 2002), Bph15 (Yang et al. 2004), bph18(t) (Li et al. 2006), Bph20(t) (Rahman et al. 2009), Bph27(t) (He et al. 2013), Bph27 (Huang et al. 2013), Bph30 (Wang et al. 2018), Bph34 (Kumar et al. 2018) and Bph36 (Li et al. 2019b) and Bph41 (Wang X et al2021) have been mapped on chromosome 4 and eight genes, Bph1 (Kim and Sohn, 2005), bph2 (Sun et al. 2006), Bph10 (Nguyen and Bui 2003), Bph9 (Su et al. 2006), Bph18(t) (Jena et al. 2006), Bph19(t) (Chen et al. 2006), Bph21(t) (Rahman et al. 2009) and Bph26(t) (Yara et al. 2010) were mapped on chromosome 12 suggesting these two chromosomes as hotspots for BPH resistance genes in rice against biotype 1, 2 and 3. This phenomenon of distribution of genes on chromosomes in clusters is consistent with the pattern of $\mathrm{R}$ genes (Mizuno et al. 2020). However, only a few of the BPH resistance genes showed broad-spectrum resistance in monogenic rice lines (Horgan et al. 2015) and the majority of the genes identified are ineffective against the evolving BPH

Page 2/16 
biotype(s) prevalent in North-Western India (Sarao et al. 2016). Thus, scouting of new genes conferring BPH resistance against Biotype 4 is urgently required.

Wild species of rice are the reservoir for many biotic and abiotic stress resistance genes (Brar and Khush, 1997). Wild species including 0 . latifolia, 0 . minuta, 0 . eichingeri 0 . nivara, 0 . australiensis, 0 . rufipogon, 0 . officinalis, and 0 . punctata have been reported to carry resistance genes against different evolving BPH biotypes (Wu et a/1986). Most of the distant genomes are still untapped because of the several fertilization barriers. The transfer of genes from related "AA" genome species is relatively easier than distantly related species due to the high level of homology at the chromosome level.

At Punjab Agricultural University, India, the wild species of rice $O$. rufipogon $(2 n=2 X=24)$ carrying AA genome was identified as a promising resistance source against Biotype 4 of BPH over the past 4 years of screening. A mapping population was developed by hybridizing O. rufipogon accession CR100441 (BPH resistant) and Punjab Rice 122 (PR122) (BPH susceptible) with the objectives of understanding the genetics of resistance and identification of chromosomal location and markers linked to resistance gene for the efficient transfer of $\mathrm{BPH}$ resistance to the elite rice cultivars.

\section{Materials And Methods}

\section{Plant materials and development of mapping population}

A collection of 1003 wild accessions of rice were screened against BPH biotype 4 at Punjab Agricultural University (PAU), Ludhiana, Punjab, India during the years 2012 and 2013, and 159 resistant accessions were identified (Sarao et al. 2016). Out of identified resistant accessions, one highly resistant 0 . rufipogon accession (CR100441) (Score 1) was selected as a donor for genetic analysis, mapping, and transfer of BPH resistance. The 0 . rufipogon accession CR100441 was crossed with high-

yielding but highly susceptible cultivar PR122 to generate $F_{1}$. The $F_{1}$ hybrid was backcrossed with PR122 to generate $B C_{1} F_{1}$. The $\mathrm{BC}_{2} \mathrm{~F}_{2}$ population and $\mathrm{BC}_{2} \mathrm{~F}_{3}$ progenies were used for the genetic analysis and mapping of the $\mathrm{BPH}$ resistant locus (Supplementary Fig. 1).

\section{Raising and maintaining BPH}

The seeds of the susceptible rice cultivar Taichung Native 1 (TN1) were sown in the earthen pots filled with puddled clay soil and plants were allowed to grow for 30 days under the insect-proof glasshouse conditions before feeding to insects. BPH biotype 4 insect culture was maintained on the 30 days old TN1 susceptible plants in a separate glasshouse maintained at $28 \pm 2^{\circ} \mathrm{C}$ and $75 \pm 5 \%$ relative humidity. Rectangular cages made of steel $(0.68 \times 0.50 \times 0.50 \mathrm{~m})$ covered with nylon size stitched along all sides except the top were used for rearing the test insect. For screening purposes, the $2^{\text {nd }}$ and $3^{\text {rd }}$ instar nymphs obtained thereafter were then released on the screening tray (Sarao et al. 2016).

\section{Phenotypic screening}

The seedling of $\mathrm{BC}_{2} \mathrm{~F}_{2}, \mathrm{BC}_{2} \mathrm{~F}_{3}, \mathrm{BC}_{2} \mathrm{~F}_{4}$, and $\mathrm{BC}_{2} \mathrm{~F}_{5}$ populations were screened using the standard seedbox screening technique (SSST) proposed by Heinrichs et al. (1985). For screening of $\mathrm{BC}_{2} \mathrm{~F}_{2}$ population, 276 pre-germinated seeds of each individual along with parents were sown in wooden/plastic trays $(45 \mathrm{~cm} \times 35 \mathrm{~cm} \times 10 \mathrm{~cm})$ containing well-puddled soil (Supplementary Fig. 2a). An insect-proof greenhouse was used to raise the progenies which were maintained at $30 \pm 2{ }^{\circ} \mathrm{C}, 80 \pm 5 \%$ relative humidity. After 14 days, the $2^{\text {nd }}$ to $3^{\text {rd }}$ instar nymphs of the hopper were released at 10-12 nymphs per seedling (Supplementary Fig. 2b). The wooden trays were covered with a fine-gauge nylon net on the iron cage (Supplementary Fig. 2c). The damage score was recorded following a 0-9 scale using the Standard Evaluation System (SES) when all seedlings of TN1 were dead. Each plant was scored as $0=$ no visible damage, $1=$ partial yellowing of the first leaf, $3=$ first and second leaves of most of the plants partially yellow, $5=$ pronounced yellowing and stunting or about half of the plants wilted or dead, $7=$ more than half plants wilted or dead and remaining plants severely stunted, $9=$ all plants wilted and dead (International Rice Research Institute (IRRI), 1996). For the evaluation of $\mathrm{BC}_{2} \mathrm{~F}_{2}$ population, the plants with damage scores 1-3 were scored as resistant and 7-9 were scored as susceptible, (Supplementary Fig. 2d). 
Further, $233 \mathrm{BC}_{2} \mathrm{~F}_{3}$ phenotypically superior lines with desirable characteristics were screened by sowing 30 seeds derived from single $\mathrm{BC}_{2} \mathrm{~F}_{2}$ plants in each row along with the resistant and recurrent parent. The evaluation of $\mathrm{BC}_{2} \mathrm{~F}_{3}$ family was done by averaging the damage score of 30 seedlings planted in each row. Based on the standard evaluation system, the mean score of each family with 0-4, 4.1-7, and 7.1-9.0 were regarded as resistant, segregating, and susceptible, respectively (Heinrichs et al. 1985). The same criterion was followed for the evaluation of $\mathrm{BC}_{2} \mathrm{~F}_{4}$ and $\mathrm{BC}_{2} \mathrm{~F}_{5}$ progenies All resistant plants were screened twice to confirm their resistance. The descriptive statistics and distribution of $\mathrm{BC}_{2} \mathrm{~F}_{3}, \mathrm{BC}_{2} \mathrm{~F}_{4}$, and $\mathrm{BC}_{2} \mathrm{~F}_{5}$ individuals were calculated using the ggplot2 package in R software (https://ggplot2.tidyverse.org). A Chi-square test for goodness of fit was used to study the inheritance pattern of resistance against BPH in each population.

\section{DNA extraction and construction of extreme bulks}

The genomic DNA was extracted from young leaves of 30-days old field-grown $\mathrm{BC}_{2} \mathrm{~F}_{2}$ population including PR122 and $O$. rufipogon accession CR100441 using the standard CTAB method (Saghai- Maroof et al. 1984). The genomic DNA was quantified using Nanodrop ${ }^{\mathrm{TM}} 8000$ Spectrophotometer (Thermo Scientific, USA). Further, the quality and integrity of genomic DNA were evaluated by electrophoresis the DNA on $0.8 \%$ agarose gel was stained with Ethidium Bromide and was visualized in a gel documentation system (Biorad). The genomic DNA was normalized by adding 1X Tris EDTA buffer. Each DNA sample was further diluted to $50 \mathrm{ng} / \mu \mathrm{l}$ for PCR analysis.

Based on the phenotypic evaluation of the $\mathrm{BC}_{2} \mathrm{~F}_{2}$ population, extreme bulks were prepared by pooling the equal concentration of the DNA from ten highly resistant individuals and ten highly susceptible individuals to make resistant bulk (RB) and ten highly susceptible (SB) respectively. The RB and SB were prepared in three replications, each bulk consisting of 10 different individuals in equal concentrations.

\section{Genotyping using rice SSR markers}

A parental polymorphism survey between PR122 and O. rufipogon acc. CR100441 was conducted using 558 SSR markers reported by Orjuela et al. (2010) and Temnykh et al. (2000) distributed over the 12 chromosomes of rice. The polymorphic markers were used for BSA to identify the linked markers. The Polymerase chain reaction (PCR) was applied on two bulked genotypes i.e., RS and SB including PR122 and O. rufipogon acc. CR100441. The SSR markers were amplified in a total of $10 \mu \mathrm{l}$ PCR reaction containing $50 \mathrm{ng}$ of genomic DNA $(25 \mathrm{ng} / \mu \mathrm{l}), 10 \mathrm{pmol}$ of each primer, $2.5 \mathrm{mM}$ each of dATP, dTTP, dGTP, and dCTP, 1 unit of Taq DNA polymerase (Promega), 1 X PCR buffer, and $1.5 \mathrm{mM} \mathrm{MgCl}_{2}$. Reactions were performed in a thermal cycler (Eppendorf) programmed at $94^{\circ} \mathrm{C}$ for $5 \mathrm{~min}$, followed by 35 cycles of $1 \mathrm{~min}$ at $94{ }^{\circ} \mathrm{C}, 1 \mathrm{~min}$ at $56^{\circ} \mathrm{C}$, and $1 \mathrm{~min}$ at $72{ }^{\circ} \mathrm{C}$ with a final extension of $7 \mathrm{~min}$ at $72^{\circ} \mathrm{C}$. PCR amplified products were resolved in $3 \%$ agarose gel and individual alleles were scored in correspondence to parental alleles. Further, identified linked markers were applied to the mapping population for QTL analysis.

\section{Linkage map construction and QTL mapping}

The linkage map was constructed using ICI Mapping software ver. 4.0 (Meng et al. 2015). A Chi-square test was performed to check the normal Mendelian behavior of the markers. SSR markers with distorted segregation were excluded from the linkage analysis and those having clean segregation patterns were subjected to linkage map construction. The Kosambi function was used to estimate map distance and most likely orders were preferred to plot the linkage map. A default logarithm of odds (LOD) threshold was used for grouping the anchored markers. After grouping, all markers, ordering using nnTwoOpt algorithm (nearest neighbor for tour construction, and two-opt for tour improvement) was selected to construct the genetic linkage map. Each group was rippled separately with SARF (sum of adjacent recombination fractions) criteria. QTL mapping was also performed using Windows QTL Cartographer (Version 2.5_011) mapping software. A LOD score of 3.0 was used as the threshold for detecting QTL location. In correspondence of phenotypic values and SSR marker data of $276 \mathrm{BC}_{2} \mathrm{~F}_{2}$ individuals, the position of QTL was identified by the Inclusive Composite Interval Mapping (ICIM) function.

\section{Phenotypic evaluation of $\mathrm{BC}_{2} \mathrm{~F}_{5}$ population for agronomic traits}


The set of $224 \mathrm{BC}_{2} \mathrm{~F}_{5}$ progenies, recipient parent PR122 and donor parent 0 . rufipogon accession CR100441 were planted in a randomized complete block design (RBD) with a plot size of $7.68 \mathrm{~m}^{2}$ in three replications. The crop was raised following recommended agronomic practices. Observations on yield and yield components along with other traits were recorded. Briefly, plant height was measured on five randomly chosen plants from ground level to the tip of the tallest panicle and averaged, tillers were counted from five plants, randomly chosen at two places from inner rows; grains number per panicle were recorded by counting total grains (including sterile spikelets) from five panicles each in five randomly-chosen plants and grain weight was recorded by weighing fertile, filled 1,000 grains counted from a bulk of ten spikes. Data recorded for the above traits were subjected to statistical analysis as per the analysis of variance for RBD using SAS software ver. 9.2 (SAS Institute Inc., 2003) and interpretations were made accordingly.

\section{Results}

\section{Phenotyping and inheritance study}

The mean BPH damage score between the two parents differed markedly in both years 2012 and 2013 (Fig. 1a). The genetic analysis of resistance present in $O$. rufipogon was studied in $\mathrm{BC}_{2} \mathrm{~F}_{3}, \mathrm{BC}_{2} \mathrm{~F}_{4}$, and $\mathrm{BC}_{2} \mathrm{~F}_{5}$ populations (Supplementary Table 1). The inheritance pattern of genetic loci conferring $\mathrm{BPH}$ resistance was confirmed using screening of 276 individual $\mathrm{BC}_{2} \mathrm{~F}_{2}$ plants, out of which 66 plants were found resistant and 210 plants were susceptible fitting to 3 (Susceptible): 1 (Resistant) segregation ratio $\left(\chi_{c}^{2}=0.17 \leq 3.8, \chi^{2}{ }_{0.05,1}\right)$ (Fig. 1b). The segregation ratio indicates the recessive nature of the BPH resistance gene of $O$. rufipogon. The $\mathrm{BC}_{2} \mathrm{~F}_{3}$ population was used to confirm the inheritance of $\mathrm{BPH}$ resistance in O. rufipogon acc CR100441. Out of $233 \mathrm{BC}_{2} \mathrm{~F}_{3}$ progenies, 52 progenies were resistant, 109 were segregating and 72 were susceptible. The segregation ratio was as per the 1:2:1 ratio $\left(\chi^{2}{ }_{c}=4.42 \leq \chi^{2}{ }_{0.05,2}=5.99\right)$, thus confirming a single major genetic locus controlled BPH resistance (Table 1). Further, genetic analysis was extended to $224 \mathrm{BC}_{2} \mathrm{~F}_{4}$ and $\mathrm{BC}_{2} \mathrm{~F}_{5}$ progenies where the $\mathrm{BPH}$-resistance scores of $\mathrm{BC}_{2} \mathrm{~F}_{4}$ population showed a continuous distribution with 106 resistant plants (1-5.5) and 118 susceptible plants (5.6-9.0) presented an acceptable fit to $1: 1$ ratio $\left(\chi^{2}{ }_{c}=0.64<\chi^{2}{ }_{0.05,1}=3.84\right)$ (Fig. 1c). The similar trend was observed in $\mathrm{BC}_{2} \mathrm{~F}_{5}$ lines with 97 resistant $\left(1-5.5\right.$ score) and 127 susceptible lines (5.6-9.0 score) owing to $\chi_{c}^{2}=3.1<\chi_{0.05,1}^{2}=3.84$. These results exhibit the presence of a single QTL determining BPH resistance in the selected mapping population. In addition, the distribution of mean damage score of $\mathrm{BC}_{2} \mathrm{~F}_{3}$ was primarily bimodal and skewed toward the susceptible parent PR122. However, the bimodal distribution of mean damage score in $\mathrm{BC}_{2} \mathrm{~F}_{4}$ and $\mathrm{BC}_{2} \mathrm{~F}_{5}$ was more prominent and stabilized (Fig. 2)

\section{Molecular mapping of the BPH resistance gene}

A total of 194 polymorphic SSR markers throughout the genome were applied to RB, SB, and two parental lines for BSA (Supplementary Table 2). The only SSR marker RM16335 located on the short arm of chromosome 4 showed linkage to the RB as per BSA (Fig. 3a). This provided the primary indication of the presence of the genetic loci on chromosome 4S that confers resistance to BPH. The RM16335 was also applied on the open bulks showed concurrence with the BSA (Fig. 3b). The polymorphic SSR markers were applied to the $\mathrm{BC}_{2} \mathrm{~F}_{2}$ population for precise mapping of the identified gene. Out of 196 polymorphic markers, 56 markers segregating in the population were used further for mapping while the remaining markers showed distorted segregation patterns (Supplementary Table 3).

\section{QTL analysis}

To further confirm the effect of QTL, the linkage map was constructed using the $\mathrm{BC}_{2} \mathrm{~F}_{2}$ mapping population covering 12 chromosomes with a total map length of $648.04 \mathrm{cM}$. The BPH resistant locus was mapped on the short of chromosome 4 flanked by SSR markers RM16282 and RM6659 at 40.76 LOD score exhibiting 29\% phenotypic variance. This locus was tentatively designated as bph42. The RM16335 was a peak marker that was closely associated with the bph42 (Fig. 3c). The map distance between the flanking markers RM16282 and RM16335 was 6 cM (Fig. 4).

\section{Validation and transfer of bph42 locus}


To validate this tightly linked marker, $224 \mathrm{BC}_{2} \mathrm{~F}_{5}$ progenies were genotyped with the peak marker RM16335 exhibited an equal ratio of amplicons corresponding to donor and recurrent parent. The marker RM16335 was perfectly co-segregating with the bph42 locus which could be utilized in the MAS program for transferring the bph42 locus into cultivated rice (Supplementary Fig. 3).

\section{Identification of superior resistant lines for varietal release}

The significant variation observed for different agronomic traits in the $\mathrm{BC}_{2} \mathrm{~F}_{5}$ population derived from PR122/O. rufipogon acc. CR100441 (Table 2). The resistant $\mathrm{BC}_{2} \mathrm{~F}_{5}$ individual showing desirable agronomic traits such as high tiller number and thousand-grain weight and optimum plant height were selected (Supplementary Fig. 4). Considerable variation was observed for plant height (71.6-111.6 cm), the number of panicles/plant (22.6-25.6), grains/panicle (157.6-141.6), and thousand-grain weight. (26.70gm-22.40gm). A maximum increment of $26.11 \%$ was observed for the number of tillers per plant in Line 144 , $15.88 \%$ for grains/panicle in Line76, and thousand-grain weight $25.35 \%$ increment was observed in L-244. These outperforming lines directly or indirectly can be used in crop improvement programs. Transgressive segregation reported for plant height, panicle per plant, grains/panicle, and 1000-grain weight indicates the contribution of beneficial alleles from the wild parent. The above observation showed that the bph42 controls the BPH resistance in rice without any yield penalty which could be used for breeding high yielding cultivars with enhanced $\mathrm{BPH}$ resistance.

\section{Discussion}

\section{0. rufipogon as potential donors for biotic stress and productivity traits}

In this study, we reported the genetic analysis and mapping of a major recessive $\mathrm{BPH}$ resistance locus bph42 on the short arm of chromosome 4 from 0 . rufipogon accession CR100441. Being a progenitor of cultivated rice, 0 . rufipogon is one of the most studied wild relatives of rice serving as a rich reservoir for many useful traits and stress resistance genes. 0 . rufipogon alsoacts as a rich pool of favorable alleles for numerous agriculturally important traits including biotic and abiotic stress tolerance genes (Neelam et al.2018). At PAU, an active collection of $\sim 400$ accessions of $O$. rufipogon were screened for various useful agronomic traits and disease resistance. Of which, useful donors were identified for resistance against BPH biotype 4 (Sarao et al. 2016), resistance to the most recently evolved pathotypes of Xanthomonas oryzae pv. oryzae (Xoo) PbXo-10 and PbXo8 (Neelam et al. 2017a). In 2011, Zhou et al. used O. rufipogon as a donor for transfer of bacterial blight resistance gene named Xa23 against Chinese (C1-C7), Philippine (P1-P10), and Japnese (T1-T3) races. Approximately, 182 accessions of $O$. rufipogon were investigated for phosphorus uptake efficiency. Among them, IRGC104639, IRGC104712, and IRGC105569 have been identified to possess novel alleles of Phosphorus uptake 1 (Pup1) locus which could be used as potential resources for improving phosphorus uptake efficiency in rice (Neelam et al. 2017b). For improving yield potential, 1780 backcross inbred lines (BILs) were developed by hybridization of 70 accessions of six wild species including 0 . rufipogon and six of them are recognized as promising donors for improving yield in cultivated rice by introgression of yield-enhancing QTLs (Bhatia et al. 2017, Bhatia et al. 2018). Xiao et al. (1998) identified QTL for panicle length (p/1.1, p/1.2, p/2.1, p/4.1, p/8.1, p/9.1 \& p/9.1), spikelets per panicle (spp1.1, spp1.2 and spp9.1), grains per panicle (gpp1.1, gpp8.2, and gpp12.1), spikelet fertility percentage (pss2.1 and pss4.1), and 1000-grain weight (gw4.1, gw8.1, gw9.1, gw11.1, and gw12.1) from 0. rufipogon in interspecific $\mathrm{BC}_{2}$ testcross population.

\section{Segregation distortion}

In our analysis, we observed that the SSR markers were distorted towards the alleles from 0 . sativa on chromosomes 2,5 , and 6. The phenomena of segregation distortion are frequently seen in inter-specific and inter-subspecific crosses. The reason behind this could be attributed to the presence of the gametophytic gene/ gamete eliminator gene which is responsible for the distorted transmission of the gametes (Xu 2008, Shanmugavadivel et al. 2013). Segregation distortion also affects the detection power of QTL when these loci are linked to the QTL leading to spurious detection of QTLs (Zhang et al. 2010). A study where the $S 1$ locus responsible for gamete elimination was mapped from 0 . glaberrima on the rice chromosome 6 . Another gene, $S 10$ was mapped on the same location as $S 1$ in an inter-subspecific cross derived from Indica and japonica cross. The 
segregation distortion locus S6 has already been reported in wild rice O. rufipogon (Koide et al., 2008; Sano, 1992). Bing et al. (2006) also reported segregation distortion on chromosomes 2, 3, and 6 in the $F_{2}$ population derived from a subspecific cross between Nipponbare and Guanglui-4. It is evident from the above-cited reports that the segregation distortion loci are an integral part of the wild Oryza genome which diverges from the primary gene pool. Observation of strong marker segregation distortion provides an opportunity to understand the biological evolution of the gametophyte /sterility gene inherited from the wild relatives of rice.

\section{A novel recessive gene bph42 confers resistance to BPH}

So far, a total of $13 \mathrm{BPH}$ resistance QTLs have been mapped into two distinct clusters on chromosome 4. Among them, 8 (Bph3/Bph17, Bph12(t),Bph15,Bph20(t),Bph30,Bph36,Bph41, and QBph4.3) are clustered on the short arm of chromosome 4 (Sun et al. 2005, Yang et al. 2002, Yang et al. 2004, Rahman et al. 2009, Wang et al. 2018, Li et al. 2019b, Wang X et al 2021 and Mohanty et al. 2017) whereas, 5 genes (Bph6, Bph27, bph18(t), Bph27(t), and Bph34) are grouped on the long arm of chromosome 4 (Qiu et al. 2010, Huang et al. 2013, Li et al. 2006, He et al. 2013, Kumar et al. 2018). Based on the marker information, Bph3/Bph17, Bph12(t),Bph15, Bph20(t),Bph36, and Bph41 were located in the sub-telomeric region of chromosome 4, hence doesn't coincide with the position of bph42. Only two of the reported genes Bph30 and QBph4.3 located in the same region (Fig. 5).In the present report, the bph42 completely covers Bph30 and partially Qbph4.3. The Bph30 and QBph4.3 are dominant (Wang et al. 2018, Mohanty et al. 2017) in nature whereas bph42 identified in this study is recessive in action indicating the novelty. Fine-mapping and map-based cloning of the $b p h 42$ gene may provide valuable information of candidate genes and its underlying mechanism that confers resistance to BPH in O. rufipogon. The SSR marker RM16335 tightly linked with bph42 can be effectively used for MAS providing BPH resistance into elite rice cultivars.

\section{Conclusion}

The present study demonstrates the identification of a novel recessive BPH resistance locus from 0 . rufipogon. The applicability of tightly linked markers with newly identified BPH resistance genes using MAS was shown for efficient introgression of this locus into the elite rice cultivar. These lines are also under multi-location yield trials and are in the process of varietal development. The advanced backcross populations developed in this study can serve as an important genetic resource for prebreeding programs to broaden the genetic base of elite rice cultivars, particularly for yield-enhancing traits with enhanced resistance to $\mathrm{BPH}$.

\section{Declarations}

\section{Acknowledgements}

The authors gratefully acknowledge the National Rice Research Institute, Cuttack for providing seed material. This work was supported by ICAR under the Project 'Molecular breeding for improvement of tolerance to biotic and abiotic stresses, yield and quality traits in Crops-Rice, Department of Biotechnology, New Delhi (BT/PR31; 75/ATGC/127/5/2019) and Department of Science and Technology, New Delhi (CRG/2018/001833).

\section{Data availability}

All the data generated and analyzed in this study are available in this article as supplementary material.

\section{Funding}

This work was supported by ICAR under the Project 'Molecular breeding for improvement of tolerance to biotic and abiotic stresses, yield and quality traits in Crops-Rice, Department of Biotechnology, New Delhi (BT/PR31; 75/ATGC/127/5/2019) and Department of Science and Technology, New Delhi (CRG/2018/001833).

\section{Competing Interest}


The authors declared no conflict of interest.

\section{Authors' contribution}

Kumari Neelam, Kuldeep Singh, Yogesh Vikal: Conceptualization of the research, proofreading of the manuscript; Pavneet Kaur carried out all the genotyping and phenotyping of the mapping population; Kumari Neelam, Kishor Kumar, Ankita Babbar: Investigation, data analysis, writing of the original draft; Preetinder Singh Sarao provided BPH biotype 4 and screening facility; Renu Khanna, Rupinder Kaur, Gurjeet Singh Mangat: Handling of segregating generation, breeding and generation advancement, management of multi-location trials. All co-authors approved this manuscript before submission."

\section{Ethics approval}

This article does not contain any studies with human participants or animals performed by any of the authors.

\section{Consent to participate}

Informed consent was obtained from all individual participants included in the study.

\section{Consent to publish}

Additional informed consent was obtained from all individual participants included in this study.

\section{References}

1. Bhatia D, Joshi S, Das A, Vikal Y, Sahi GK, Neelam K, Kaur K, Singh K (2017) Introgression of Yield Potential Component Traits in Rice (Oryza sativa ssp. indica) through Interspecific Hybridization.Crop Sci 57: 1557-1573

2. Bhatia D, Wing RA, Yu Y, Chougule K, Kudrna D, Lee S, Rang A, Singh K (2018) Genotyping by sequencing of rice interspecific backcross inbred lines identifies QTLs for grain weight and grain length. Euphytica 214: 41, 10.1007/s10681018-2119-1.

3. Bing Z, Qi-Ming D, Zhang Q, Jie-Qin L, Shao-Ping Y, Liang Y, Yong P and Ping L (2006) Analysis of segregation distortion of molecular markers in F2 population of rice. Acta Genetica Sinica, 33(5): 449-457.

4. Bisht DS, Bhatia V, Bhattacharya R (2019) Improving plant resistance to insect-pests and pathogens: The new opportunities through targeted genome editing.Semin Cell Dev Biol96: 65-76.

5. Brar DS, Khush GS (1997) Alien introgression in rice.Plant Mol Biol35: 35-47.

6. Chen JW, Wang L, Pang XF, Pan H (2006)Genetic analysis and fine mapping of a rice brown plant hopper (Nilaparvata lugens Stal) resistance gene bph19(t). Mol Genet Genom 275: 321-329.

7. Elanchezhyan K, Sathyan T, Manikandan KR (2020) Brown Plant Hopper (BPH) and Their Management in Rice. Biotica Research Today 2: 090-092.

8. Frisvold GB (2019) How low can you go? Estimating impacts of reduced pesticide use. Pest Manag Sci 75: 1223-1233.

9. He J, Liu YQ, Liu YL, Jiang L, Wu H, Kang HY, Liu SJ, Chen LM, Liu X, Cheng XN, Wan JM (2013) High-resolution mapping of brown planthopper (BPH) resistance gene Bph27(t) in rice (Oryza sativa L.). Mol Breed 31: 549-557.

10. Heinrichs EA, Medrano FG, Rapusas HR (1985) Genetic Evaluation for Insect Resistance in Rice. Los Baños, the Philippines: International Rice Research Institute. http://books.irri.org/97110 41103_content.

11. Horgan FG, Ramal AF, Bentur JS, Kumar R, Bhanu KV, Sarao PS, Iswanto ES, Chien HV, Phyu MH, Bernal CC, Almazan ML, Alam MZ, Lu Z, Huang S (2015) Virulence of brown planthopper (Nilaparvata lugens) populations from south and South East Asia against resistant rice varieties. Crop Prot 78: 222-231.

12. Huang D, Qiu Y, Zhang Y, Huang F, Meng J, Wei S, Li R, Chen B (2013) Fine mapping and characterization of $B P H 27$, a brown planthopper resistance gene from wild rice (Oryza rufipogon Griff.).Theor Appl Genet 126: 219-229. 
13. International Rice Research Institute (IRRI) (1996) Standard Evaluation System for Rice.Los Baños, Philippines: International Rice Research Institute. pp 30-31.

14. Jena KK, Jeung JU, Lee JH, Choi HC, Brar DS (2006) High resolution mapping of a new brown plant hopper (BPH) resistance gene, Bph18(t), and marker-assisted selection for BPH resistance in rice (Oryza sativa L.). Theor Appl Genet 112 : 288-297.

15. Kim SM, Sohn JK (2005) Identification of rice gene (Bph1) conferring resistance to brown planthopper (Nilaparvata lugens Stal) using STS markers. Mol Cells 20: 30-34.

16. Koide $\mathrm{Y}$, Ikenaga $\mathrm{M}$, Sawamura N, et al (2008) The evolution of sex-independent transmission ratio distortion involving multiple allelic interactions at a single locus in rice. Genetics 180:409-420. doi: 10.1534/genetics.108.090126

17. Kumar H, Maurya RP, Tiwari SN (2012) Studies on antibiosis mechanism of resistance in rice against brown planthopper, Nilaparvata lugens(Stal.).Ann Plant Prot Sci 28: 98-101.

18. Kumar K, Kaur P, Kishore A, Vikal Y, Singh K, Neelam K (2020) Recent advances in genomics-assisted breeding of brown planthopper (Nilaparvata lugens) resistance in rice (Oryza sativa). Plant Breed 139:1052-1066.

19. Kumar K, Sarao PS, Bhatia D, Neelam K, Kaur A, Mangat GS, Brar DS, Singh K (2018) High-resolution genetic mapping of a novel brown planthopper resistance locus, Bph34 in Oryza sativa L. X Oryza nivara (Sharma \& Shastry) derived interspecific $\mathrm{F}_{2}$ population. Theor Appl Genet 131: 1163-1171.

20. Li J B, Xia MY, He GC, Wan BL, Zha ZP (2006) Marker-assisted selection for brown palnt hopper locus in rice.Maejo International Journal on Science. International Rice Research Institute.

21. Li Z, Xue Y, Zhou H, Li Y, Usman B, Jiao X, Wang X, Liu F, Qin B, Li R, Qiu Y (2019b) High-resolution mapping and breeding application of a novel brown planthopper resistance gene derived from wild rice (Oryza. rufipogon Griff).Rice 12. 10.1186/s12284-019-0289-7.

22. Meng L, Li H, Zhang L, Wang J (2015) QTL IciMapping: integrated software for genetic linkage map construction and quantitative trait locus mapping in biparental populations.Crop J 3: 269-283.

23. Mizuno H, Katagiri S, Kanamori H, Mukai Y, Sasaki T, Matsumoto T, Wu J (2020) Evolutionary dynamics and impacts of chromosome regions carrying R-gene clusters in rice.Sci rep 10,10.1038/s41598-020-57729-w.

24. Mohanty SK, Panda RS, Mohapatra SL, Nanda A, Behera L, Jena M, Sahu RK, Sahu SC, Mohapatra T (2017) Identification of novel quantitative trait loci associated with brown planthopper resistance in the rice landrace Salkathi.Euphytica38. 10.1007/s10681-017-1835-2.

25. Neelam K, Lore J, Pathania S, Kumar K, Sahi G, Mangat GS, Singh K (2017a) Identification of resistance sources in wild species of rice against two recently evolved pathotypes of Xanthomonas oryzaepv oryzae. Plant Genet Resour 15: 558562.

26. Neelam K, Malik P, Kaur K, Kumar K, Jain S, Neha, Singh K (2018) Oryza rufipogonGriff. The Wild Oryza Genomes,Compendium of Plant Genomes. 10.1007/978-3-319-71997-9_25.

27. Neelam K, Thakur S, Neha, Yadav IS, Kumar K, Dhaliwal SS, Singh K(2017b) Novel Alleles of Phosphorus-Starvation Tolerance 1 Gene (PSTOL 1) from Oryza rufipogon Confers High Phosphorus Uptake Efficiency. Front Plant Sci 8. 10.3389/fpls.2017.00509.

28. Nguyen T L, Bui CB (2003) Genetic and physical maps of gene Bph10 controlling brown planthopper resistance in rice (Oryza sativa L.).Omonrice 11:35-41.

29. Orjuela J, Garavito A, Bouniol M, Arbelaez JD, Moreno L, Kimball J, Wilson G, Rami JF, Tohme J, McCouch SR, Lorieux M (2010) A universal core genetic map for rice. Theor Appl Genet120: 563-572.

30. Pathak MD, Cheng CH, Fortuno ME (1969) Resistance to Nephotettix impicticeps and Nilaparvata lugens in varieties of rice. Nature 223: 502-504.

31. Qiu Y, Guo J, Jing S, Zhu L, He G (2010) High-resolution mapping of the brown planthopper resistance gene Bph6 in rice and characterizing its resistance in the 9311 and Nipponbare near isogenic backgrounds. Theor Appl Genet 121:1601-1611. 
32. Rahman ML, Jiang W, Chu SH, Qiao Y, Ham TH, Woo MK, Lee J, Khanam S, Chin JH, Jeung JU, Brar DS, Jena KK, Koh HJ (2009) High-resolution mapping of two brown planthopper resistance genes, Bph2O(t) and Bph21(t), originating from Oryza minuta.Theor Appl Genet 119: 1237-1246.

33. Rashid M, Ahmed N, Jahan M, Islam K S, Nansen C, Willers JL, Ali MP (2017) Higher fertilizer inputs increase fitness traits of brown planthopper in rice. Sci Rep 7: 1-16.

34. Saghai-Maroof MA, Soliman KM, Jorgensen RA, Allard RW (1984) Ribosomal DNA spacer length polymorphism in barley: Mendelian inheritance, chromosomal location and population dynamics.Proc Natl Acad Sci USA 81: 8014-8018.

35. Sano Y (1992) Genetic studies of speciation in cultivated rice. 10. Genetic Comparisons of Chromosome 6 between Wild and Cultivated Rice. Japanese J Breed 42:561-572. doi: 10.1270/jsbbs1951.42.561

36. Sarao PS, Sahi GK, Neelam K, Mangat GS, Patra BC, Singh K (2016) Donors for Resistance to Brown Planthopper Nilaparvata lugens (Stål) from Wild Rice Species. Rice Sci 23: 219-224.

37. Shanmugavadivel PS, Mithra SVA, Dokku P, et al (2013) Mapping quantitative trait loci (QTL) for grain size in rice using a RIL population from Basmati $\times$ indica cross showing high segregation distortion. Euphytica 194:401-416. doi: $10.1007 /$ s10681-013-0964-5

38. Srivastava C, Chander S, Sinha SR, Palta RK (2009) Toxicity of various insecticides against Delhi and Palla population of brown planthopper (Nilaparvata lugens).Ind J Agric Sci 79: 1003-1006.

39. Su CC, Zhai HQ, Wang CM, Sun LH, Wan JM (2006) SSR mapping of brown planthopper resistance gene Bph9 in Kaharamana, an indica rice (Oryza sativa L.).Acta Genetica Sinica 33: 262-268.

40. Sun LH, Su CC, Wang CM, Zhai HQ, Wan JM (2005) Mapping of a major resistance gene to the brown planthopper in the rice cultivar Rathu Heenati.Breed Sci 55: 391- 396.

41. Sun LH, Wang CM, Su CC, Liu YQ, Zhai HQ, Wan J (2006) Mapping and marker-assisted selection of a brown planthopper resistance genebph2 in rice (Oryza sativa L.). Acta Genetica Sinica 33: 717-723.

42. Temnykh S, Park WD, Ayres N, Cartinhour S, Hauck N, Lipovich L, Cho YG, Ishii T, McCouch SR (2000) Mapping and genome organization of microsatellite sequences in rice (Oryza sativa L.). Theor Appl Genet 100: 697-712.

43. Wang H, Shi S, Guo Q, Nie L, Du B, Chen R, Zhu L, He G (2018) High-resolution mapping of a gene conferring strong antibiosis to brown planthopper and developing resistant near-isogenic lines in 9311 background.Mol Breed 107. 10.1007/s11032-018-0859-1.

44. Wang X, Han Y, Zhang Y, Deng B, Wu B, Guo X, Qin Y, Fang Y, Liu F, Qin B, Luo J, Li R(2021) QTL Mapping Integrated with BSA-Seq Analysis Identifies a Novel Gene Conferring Resistance to Brown Planthopper from Common Wild Rice (Oryza rufipogon Griff.).Euphytica.10.21203/rs.3.rs-478718/v1

45. Win SS, Muhamad R, Ahmad ZA, Adam NA (2011) Life table and population parameters of Nilaparvata lugens Stal. (Homoptera: Delphacidae) on rice. Trop Life Sci Res 22: 25-35.

46. Wu JT, Heinrich EA, Medrano FG (1986) Resistance of wild rice, Oryza spp, to the brown plant hopper, Nilaparvata lugens (Homoptera: Delphacidae).Environ Entomol 15:648-653.

47. Xiao J, Li J, Grandillo S, Yuan L, Tanksley S D and McCouch S R (1998) Identification of traits improving quantitative trait loci alleles from wild rice relative Oryza rufipogon. Genet 150: 899-09.

48. Xu S (2008) Quantitative trait locus mapping can benefit from segregation distortion. Genetics 180:2201-2208. doi: 10.1534/genetics.108.090688

49. Yang HY, Ren X, Weng QM, Zhu LL, He GC (2002) Molecular mapping and genetic analysis of a rice brown planthopper (Nilaparvata lugens Stal) resistance gene. Hereditas 136: 39- 43.

50. Yang HY, You AQ, Yang ZF, Zhang FT, He RF, Zhu LL, He GC (2004) High-resolution genetic mapping at the Bph15 locus for brown planthopper resistance in rice (Oryza sativaL.).Theor Appl Genet110: 182-191.

51. Yara A, Phi CN, Matsumura M, Yoshimura A, Yasui H (2010) Development of nearisogenic lines for Bph25(t) and Bph26(t), which confer resistance to the brown planthopper, Nilaparvata lugens Stal in indica rice 'ADR52'.Breed Sci 60: 639-647. 
52. Zhang L, Wang S, Li H, Deng Q, Zheng A, Li P, Li Z and Wang J (2010) Effects of missing marker and segregation distortion on QTL mapping in F2 populations. Theor Appl Genet 121:1071-1082. doi: 10.1007/s00122-010-1372-z

53. Zheng X, Zhu L, He G (2020) Genetic and molecular understanding of host rice resistance and Nilaparvata lugens adaptation.Curr Opin Insect Sci 45: 14-20.

54. Zhou YL, Uzokwe VN, Zhang CH, Cheng LR, Wang L, Chen K, Gao XQ, Sun Y, Chen JJ, Zhu LH and Zhang Q (2011). Improvement of bacterial blight resistance of hybrid rice in China using the Xa23 gene derived from wild rice (Oryza rufipogon). Crop Protection, 30(6): 637-644.

\section{Tables}

Table 1: Evaluation of $\mathrm{BPH}$ damage score of $\mathrm{BC}_{2} \mathrm{~F}_{2}$ and $\mathrm{BC}_{2} \mathrm{~F}_{3}$ using Chi-square analysis

\begin{tabular}{|lcccll|}
\hline BPH damage score & $<3.5$ & $3.6-7.0$ & $7.1-9$ & $\chi^{2}$ & $\chi^{2}(0.05,1)$ \\
\hline $\mathrm{BC}_{2} \mathrm{~F}_{2}(\# 276)$ & 66 & - & 210 & $0.17(1: 3)$ & 3.84 \\
$\mathrm{BC}_{2} \mathrm{~F}_{3}(\# 233)$ & 52 & 109 & 72 & $4.42(1: 2: 1)$ & 5.99 \\
\hline
\end{tabular}

1. The number written in parenthesis is individual used in the experiment.

2. (-) represents no individuals having BPH damage score 3.6-7.0.

Table 2: Identification of BPH resistant lines with superior agronomic traits 


\begin{tabular}{|c|c|c|c|c|c|c|c|c|}
\hline \multirow{2}{*}{$\begin{array}{l}\text { Line- } \\
\text { ID }\end{array}$} & \multicolumn{8}{|l|}{ Traits } \\
\hline & $\begin{array}{l}\text { Plant } \\
\text { height } \\
\text { (cm) }\end{array}$ & $\begin{array}{l}\% \\
\text { increment }\end{array}$ & Panicles/plant & $\begin{array}{l}\% \\
\text { increment }\end{array}$ & Grains/panicle & $\begin{array}{l}\% \\
\text { increment }\end{array}$ & $\begin{array}{l}\text { Thousand } \\
\text { grain } \\
\text { weight } \\
\text { (gm) }\end{array}$ & $\begin{array}{l}\% \\
\text { increment }\end{array}$ \\
\hline 37 & $83.3 \pm 1.66$ & -19.13 & $22.6 \pm 0.33$ & 11.33 & $147.6 \pm 1.45$ & 8.53 & $22.5 \pm 0.29$ & 5.63 \\
\hline 60 & $91.6 \pm 1.66$ & -11.07 & $25.0 \pm 0.0$ & 23.15 & $150.6 \pm 2.19$ & 10.74 & $24.1 \pm 0.24$ & 13.15 \\
\hline 76 & $105.0 \pm 0.0$ & 1.94 & $24.0 \pm 0.57$ & 18.23 & $157.6 \pm 1.45$ & 15.88 & $23.1 \pm 0.32$ & 8.45 \\
\hline 90 & $100.0 \pm 0.0$ & -2.91 & $23.6 \pm 0.8$ & 16.26 & $143.3 \pm 4.41$ & 5.37 & $25.1 \pm 0.24$ & 17.84 \\
\hline 125 & $88.3 \pm 3.33$ & -14.27 & $24.3 \pm 0.66$ & 19.70 & $143.0 \pm 1.53$ & 5.15 & $24.7 \pm 0.31$ & 15.96 \\
\hline 140 & $93.3 \pm 1.66$ & -9.42 & $25.0 \pm 0.57$ & 23.15 & $151.3 \pm 4.64$ & 11.25 & $24.6 \pm 0.24$ & 15.49 \\
\hline 144 & $98.3 \pm 1.66$ & -4.56 & $25.6 \pm 0.33$ & 26.11 & $147.3 \pm 1.76$ & 8.31 & $23.1 \pm 0.32$ & 8.45 \\
\hline 150 & $71.6 \pm 30.86$ & -30.49 & $23.3 \pm 0.33$ & 14.78 & $144.0 \pm 3.03$ & 5.88 & $23.3 \pm 0.26$ & 9.39 \\
\hline 161 & $100.0 \pm 0.0$ & -2.91 & $23.6 \pm 1.85$ & 16.26 & $144.0 \pm 3.06$ & 5.88 & $23.2 \pm 0.26$ & 8.92 \\
\hline 174 & $100.0 \pm 2.88$ & -2.91 & $24.6 \pm 0.66$ & 21.18 & $141.6 \pm 6.01$ & 4.12 & $22.4 \pm 0.28$ & 5.16 \\
\hline 179 & $91.6 \pm 1.66$ & -11.07 & $23.3 \pm 0.33$ & 14.78 & $147.3 \pm 3.93$ & 8.31 & $25.2 \pm 0.20$ & 18.31 \\
\hline 197 & $85.0 \pm 0$ & -17.48 & $24.0 \pm 0.57$ & 18.23 & $147.6 \pm 2.85$ & 8.53 & $24.5 \pm 0.34$ & 15.02 \\
\hline 199 & $90.0 \pm 2.88$ & -12.62 & $24.0 \pm 1.0$ & 18.23 & $149.3 \pm 0.67$ & 9.78 & $25.2 \pm 0.43$ & 18.31 \\
\hline 244 & $111.6 \pm 1.66$ & 8.35 & $23.6 \pm 0.66$ & 16.26 & $147.0 \pm 1.73$ & 8.09 & $26.7 \pm 0.551$ & 25.35 \\
\hline 245 & $81.6 \pm 1.66$ & -20.78 & $23.3 \pm 1.45$ & 14.78 & $143.0 \pm 1.53$ & 5.15 & $23.8 \pm 0.72$ & 11.74 \\
\hline 255 & $93.3 \pm 1.66$ & -9.42 & $23.6 \pm 2.02$ & 16.26 & $148.3 \pm 6.01$ & 9.04 & $23.5 \pm 0.97$ & 10.33 \\
\hline 297 & $101.6 \pm 1.66$ & -1.36 & $23.6 \pm 1.45$ & 16.26 & $147.6 \pm 4.41$ & 8.53 & $24.9 \pm 0.15$ & 16.90 \\
\hline $\begin{array}{l}\text { PR- } \\
122\end{array}$ & 103.00 & & 20.30 & & 136.00 & & 21.30 & \\
\hline C.D. & 11.55 & & 2.39 & & 5.43 & & 1.16 & \\
\hline SE & 4.13 & & 0.85 & & 3.113 & & 0.42 & \\
\hline C.V. & 7.52 & & 6.24 & & 3.674 & & 3.26 & \\
\hline
\end{tabular}

\section{Figures}

\section{Figure 1}

(a): Screening of BPH resistant $O$. rufipogon acc. CR100441 and highly susceptible cultivar PR122. (b) Evaluation of $\mathrm{BC}_{2} \mathrm{~F}_{3}$ progenies against $\mathrm{BPH}$ biotype 4, (c) Evaluation of $\mathrm{BC}_{2} \mathrm{~F}_{4}$ population against $\mathrm{BPH}$ biotype 4 . Red arrows indicate homozygous susceptible progeny rows. 


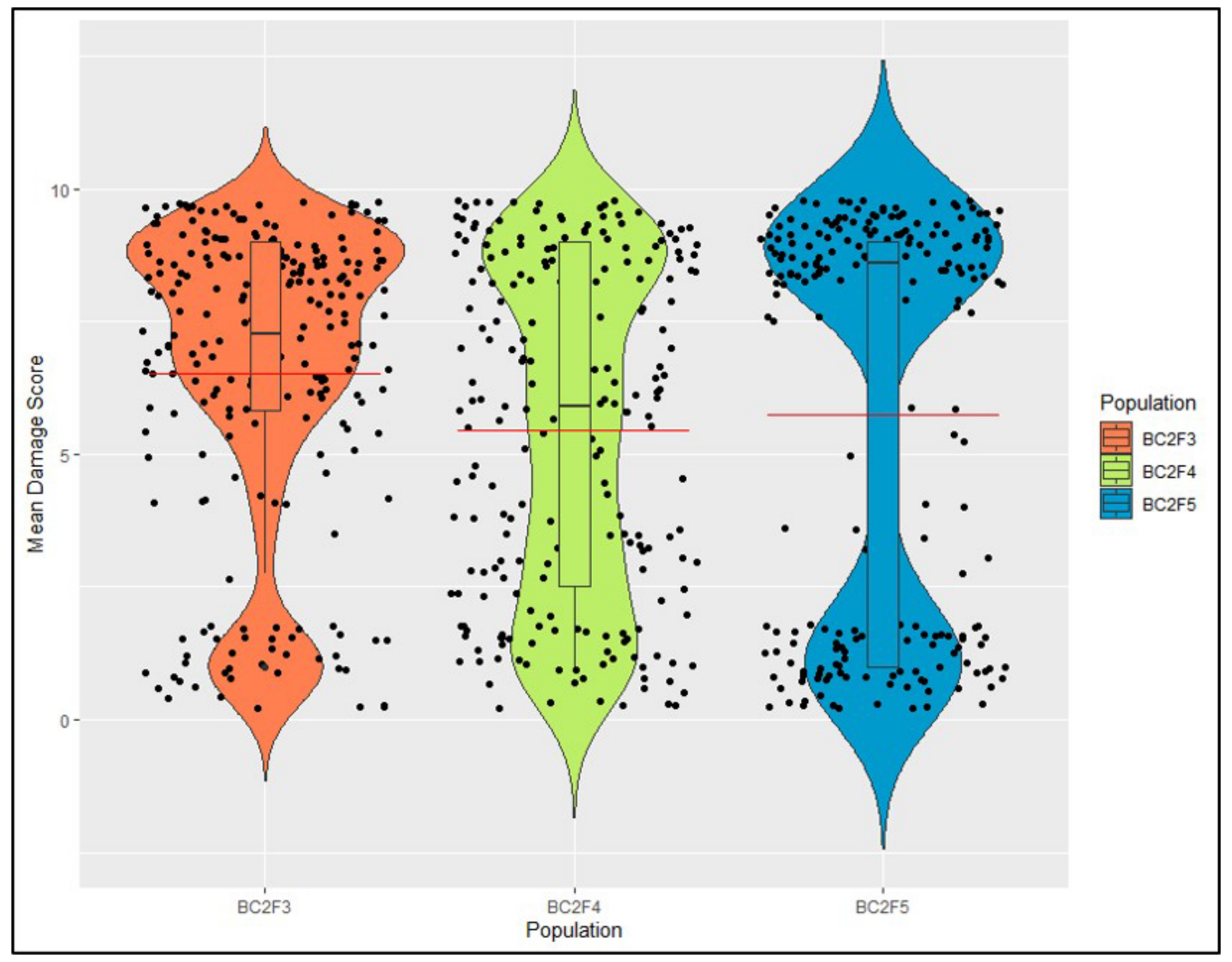

Figure 2

Violin plots showing distribution of mean damage score of $\mathrm{BC}_{2} \mathrm{~F}_{3}, \mathrm{BC}_{2} \mathrm{~F}_{4}$ and $\mathrm{BC}_{2} \mathrm{~F}_{5}$ individuals. Horizontal red bars indicate the average value.

\section{Figure 3}

Agarose gel image showing amplification of linked SSR marker RM16335 on resistant and susceptible bulks and their parental lines. (a) Amplification of RM16335 on resistant and susceptible bulks (b) Amplification of RM16335 on open bulks (c) Amplification of peak marker RM16335 on $\mathrm{BC}_{2} \mathrm{~F}_{2}$ population, parental bands correspond to PR122 and O.rufipogon acc. CR100441 are marked. 


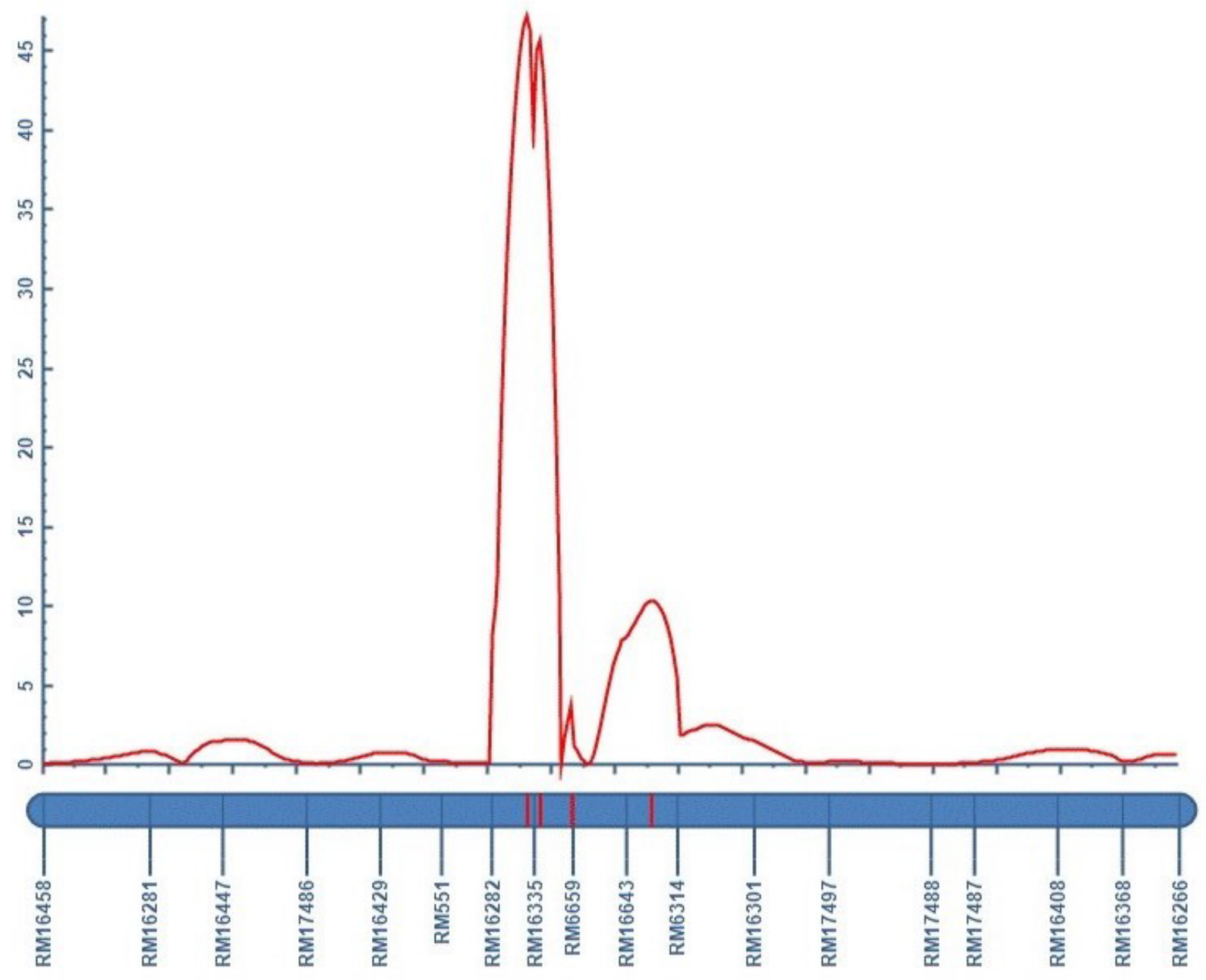

Figure 4

LOD curve showing peak of major effect locus associated with resistance to BPH on the short arm of chromosome 4. 


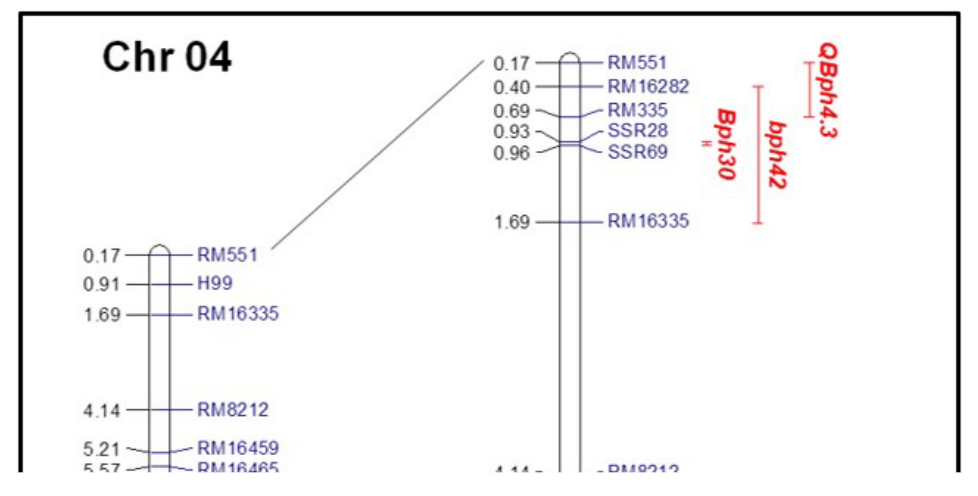

\section{Figure 5}

Linkage map of the chromosome 4 showing clusters of $\mathrm{BPH}$ resistance gene. The numbers on the left side of the bar represent physical position of the markers.

\section{Supplementary Files}

This is a list of supplementary files associated with this preprint. Click to download.

- SupplementaryFig1.jpg

- SupplementaryFig2.jpg

- SupplementaryFig3.jpg

- SupplementaryFig4.jpg

- Tables1.xIsx

- Tables2.docx 
- Tables3.xlsx

Page 16/16 